\title{
Correction to: Finite element modelling and parameter identification of the seated human body exposed to vertical vibration
}

\author{
Kaizhan Gao ${ }^{1}$. Chunyu $\mathrm{Li}^{1} \cdot$ Yang Xiao ${ }^{1} \cdot$ Zhifei Zhang $^{1}$ (I)
}

Published online: 10 September 2021

๑) Springer-Verlag GmbH Germany, part of Springer Nature 2021

\section{Correction to: Biomechanics and Modeling in Mechanobiology \\ https://doi.org/10.1007/s10237-021-01481-1}

In the original publication of the article, Fig. 4 was published with error. Figure 4 in the original article should be replaced with:


Fig. 4 Schematic diagrams of the sitting postures: a experimental posture; $\mathbf{b}$ modelled posture
In the original publication of the article, Table 9 was published with an error. In the frequency range of 4-7 Hz of Table 9, sixth column, 'Fore-and-aft motion of thigh and pelvis at $6.39 \mathrm{~Hz}$ ' was put in the wrong position, and it should belong to the six-order modal analysis result of Kim et al. (2005). The correct table is provided below.

The original article can be found online at https://doi.org/10.1007/ s10237-021-01481-1.

Zhifei Zhang

z.zhang@cqu.edu.cn

1 School of Automotive Engineering, Chongqing University,

Chongqing 400030, China 


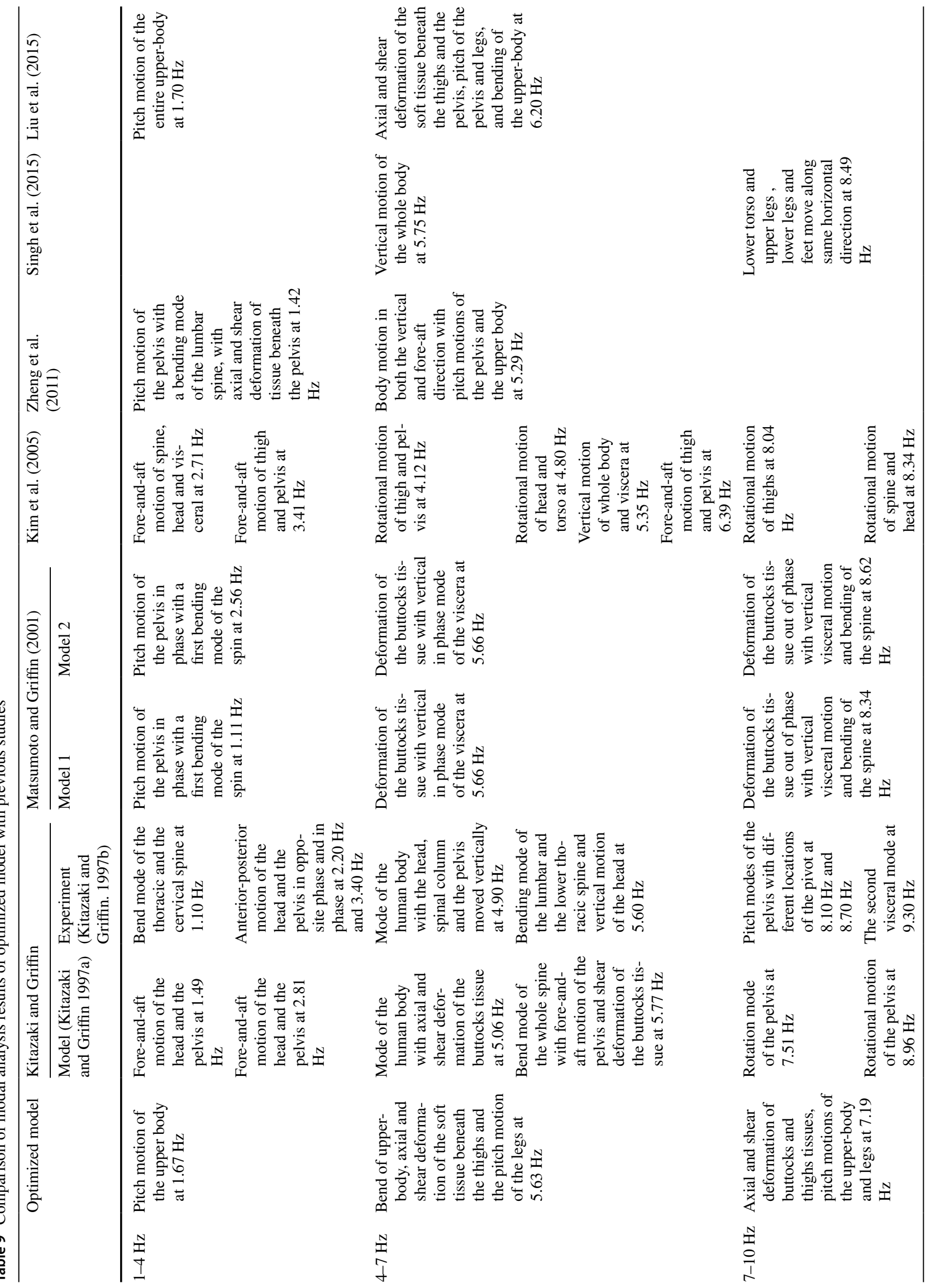


Correction to: Finite element modelling and parameter identification of the seated human body...

1807

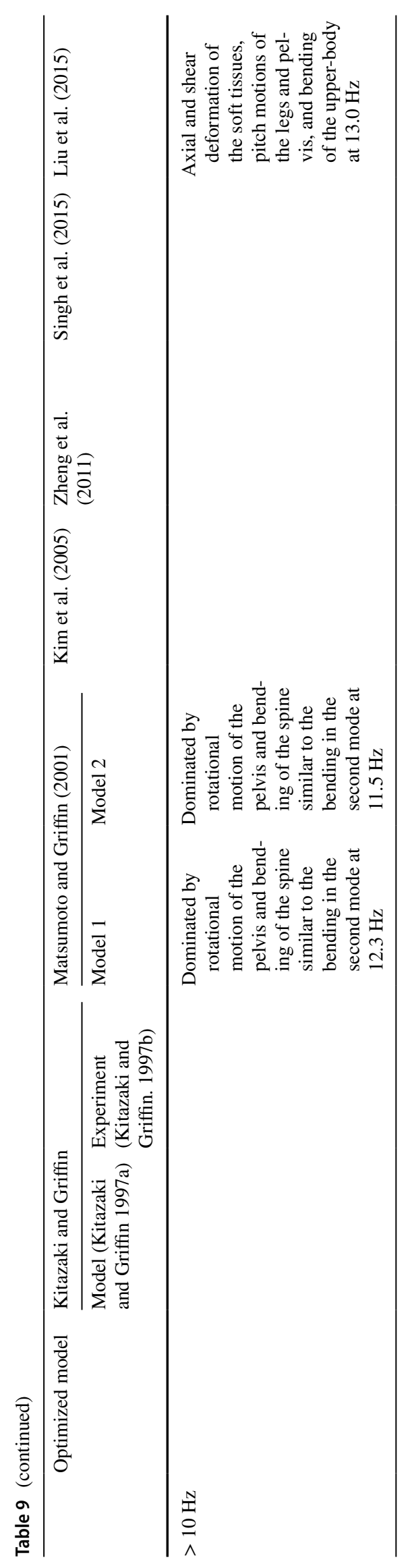

Publisher's Note Springer Nature remains neutral with regard to jurisdictional claims in published maps and institutional affiliations.

Springer 